\title{
EFFECT OF AGING ON TRANSLUCENCY AND FLEXURAL STRENGTH OF DIFFERENT ZIRCONIA MATERIALS (AN IN-VITRO STUDY)
}

\author{
Amr Hussam Alzebdah *, Ahmed M. Hamdy ${ }^{* *}$ and Alaa M. Naguib ${ }^{* * *}$
}

\begin{abstract}
Statement of Problem: Since ultra high translucent cubic zirconia was evolved in the market, comparison were made with high translucent tetragonal zirconia regarding translucency and flexural strength after thermal aging.
\end{abstract}

Aim of This Study : The aim of this study is to detect translucency and flexural strength changes of two different zirconia materials before and after aging.

Material and Methods: Forty Zirconia samples $(n=20)$ from each type (Cubic and Tetragonal Zirconia) were prepared then autoclaved. The aging parameter was set to a temperature of $134 \mathrm{C}^{\circ}$ and a pressure of 2 bar for 10 hours of aging. A spectrophotometer device was used for measurement of translucency and contrast ratio of each group. Piston and three supporting balls test were used for flexural strength test.

Results: The results showed that Zirconia type (regardless of aging) had a statistically significant effect on mean translucent parameter and flexural strength. Aging had a statistically significant effect on mean translucent parameter and flexural strength except for the cubic zirconia which showed non-significant lower flexural strength after aging.

Conclusion: Aging (regardless of Zirconia type) had a statistically significant effect on mean translucent parameter and flexural strength. Flexural strength of cubic zirconia was not significantly affected by aging.

KEYWORDS: Thermal aging, translucency, flexural strength, zirconia microstructure

\footnotetext{
* B.D.S (2015), Faculty of Dentistry, October University for Modern Sciences and Arts.

** Professor of Fixed Prosthodontics Faculty of Dentistry October University for Modern Sciences and Arts.

*** Lecturer of Fixed Prosthodontics Faculty of Dentistry October University for Modern Sciences and Arts.
} 


\section{INTRODUCTION}

Translucency of dental ceramics is one of the most important parameters to achieve esthetic restoration and making it more natural by transmission of light through ceramic materials. ${ }^{[1,2]}$

Lately $5 \mathrm{~mol} \%$ yttria high translucent partially stabilized zirconia has been developed and are available as it increases the degree of translucency through increasing the amount of cubic crystals in the material to approximately $50 \%$. However, this increase of translucency comes often on the expense of strength and toughness. These new materials were commercially available but its resistance to aging is not yet fully established. ${ }^{[2,3]}$

The mechanical performance of zirconia material might be weakened via transformation from tetragonal to monoclinic phase $(\mathrm{t} \rightarrow \mathrm{m})$ when exposed to low temperature degradation (LTD). Water is incorporated in the beginning at the superficial grains by filling oxygen vacancies, then extents into the bulk of the material and affects adversely the flexural strength and mechanical properties of Y-TZP structures. ${ }^{[3,4]}$

So, to overcome these problems, recent types of zirconia material have been presented in the dental market to improve mechanical properties with excellent esthetics.

This study was done to test and evaluate translucency and flexural strength of two different types of zirconia materials before and after accelerated aging.

\section{MATERIALS AND METHODS}

Forty zirconia samples $(n=20)$ from each type (Ultra high translucent cubic zirconia DD cubex ${ }^{2}$ and High translucent tetragonal zirconia DD Bio $\mathrm{ZX}^{2}$ ) was prepared from the blanks of both groups using Isomet 4000 . Shrinkage rate of zirconia blanks were calculated before cutting and added to the final dimensions required after sintering $(10 \times 10 \times 0.8$ $\mathrm{mm}$ ) (shrinkage rate $1.23 \%$ according to the manufacturer instructions $)(12 \times 12 \times 0.98 \mathrm{~mm}) \cdot{ }^{[4]}$
Then zirconia discs were sintered in a zirconia sintering furnace (Tegra speed).

Diasynt plus and Diacera EVE Zirconia finishing kit (Ernst Vetter GmbH Keltern, Germany) were used for finishing and polishing all samples according to manufacturer's instructions on both surfaces. 10 samples from each zirconia type were grouped and packaged separately inside a sterilization pouch, then autoclaved by Andromeda (Gima Made in Italy). The aging parameter was set to a temperature of $134 \mathrm{C}^{\circ}$ and a pressure of 2 bar for 10 hours of aging. ${ }^{[5,6]}$

All zirconia specimens were cleaned in ultrasonic cleaning device, ultrasonic cleaner (cd-4830, COXO, China) in isopropyl alcohol solution bath for a period of 10 minutes, then the samples were dried well using gentle air and stored in a labeled box for the testing step. ${ }^{[7]}$

For testing translucent parameter three measurements of $L^{*}, a^{*}$, and $b^{*}$ were recorded for each specimen and averaged to obtain a mean value for the following calculations. In the color space, $\mathrm{L}^{*}$ indicates lightness, the $\mathrm{a}^{*}$ coordinate represents the green-red range, and the $b^{*}$ coordinate represents the blue-yellow range. The translucency parameter (TP) of each specimen was determined by calculating the color difference between readings against black (B) and white (W) backgrounds for the same specimen, according to the following equation:

$$
\mathrm{TP}=\left[\left(\mathrm{L}^{*}{ }_{\mathrm{B}}-\mathrm{L}^{*}{ }_{\mathrm{W}}\right)^{2}+\left(\mathrm{a}^{*}{ }_{\mathrm{B}}-\mathrm{a}^{*}{ }_{\mathrm{W}}\right)^{2}+\left(\mathrm{b}^{*}{ }_{\mathrm{B}}-\mathrm{b}^{*}{ }_{\mathrm{W}}\right)^{2}\right]^{1 / 2}
$$

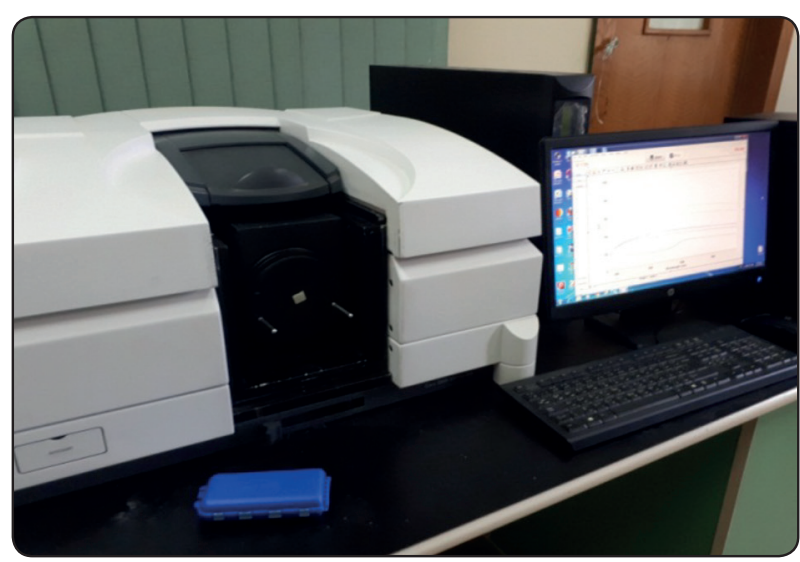

Cary 5000 spectrophotometer 


\section{Biaxial flexural strength test}

Piston and three supporting balls test was used for flexural strength test according to ISO 6872:2008. ${ }^{[8]}$

A universal testing machine (Instron, Illinois, USA) was used. Diameter of the supporting 3 balls was $2.5 \mathrm{~mm}$. Diameter of plugger applying force was $1.4 \mathrm{~mm}$. While the diameter of ring including 3 supporting balls was $10 \mathrm{~mm}$. Film of non-rigid material, as a polyethylene sheet, placed in the

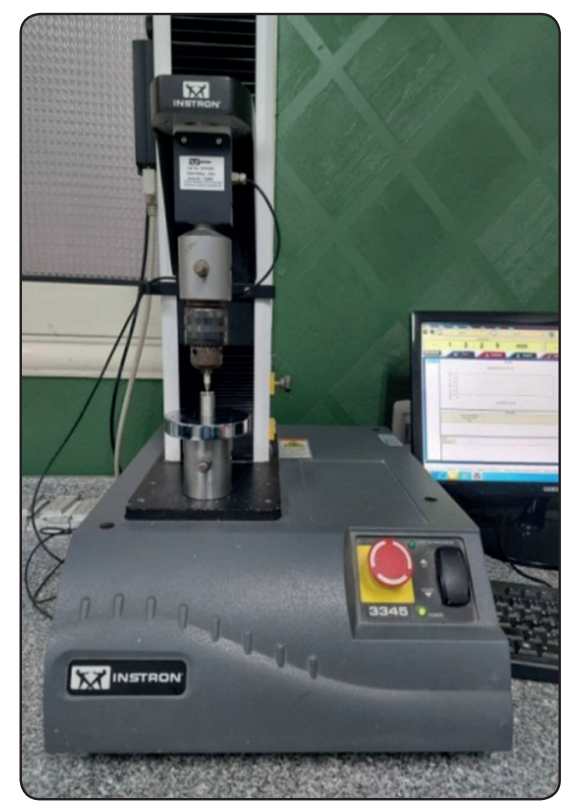

Instron univeral testing machine interface between specimen and the piston has been indicated to reduce the friction effects. Compressive mode of force applied by 5000 Newton load cell at crosshead speed $1 \mathrm{~mm} / \mathrm{min}$ up to specimen failure.

\section{RESULTS}

Numerical data were explored for normality by checking the distribution of data and using tests of normality (Kolmogorov-Smirnov and ShapiroWilk tests). All data showed parametric (normal) distribution. Data were presented as mean and standard deviation (SD) values. Two-way Analysis of Variance (ANOVA) was used to study the effect of Zirconia type, aging and their interaction on mean translucency parameter (TP) and contrast ratio (CR). Bonferroni's post-hoc test was used for pairwise comparisons when ANOVA test is significant. The significance level was set at $\mathrm{P} \leq 0.05$. Statistical analysis was performed with IBM SPSS Statistics for Windows, Version 23.0. Armonk, NY: IBM Corp

The results showed that Zirconia type (regardless of aging) had a statistically significant effect on mean translucent parameter and flexural strength. Aging had a statistically significant effect on mean translucent parameter and flexural strength except for the cubic zirconia which showed non-significant lower flexural strength after aging.

TABLE (1) Descriptive statistics for TP values

\begin{tabular}{|c|c|c|c|c|c|c|c|c|}
\hline \multirow{2}{*}{ Zirconia type } & \multirow{2}{*}{ Aging } & \multirow{2}{*}{ Mean } & \multirow{2}{*}{ SD } & \multirow{2}{*}{ Median } & \multirow{2}{*}{ Minimum } & \multirow{2}{*}{ Maximum } & \multicolumn{2}{|c|}{$95 \% \mathrm{CI}$} \\
\hline & & & & & & & Lower bound & Upper bound \\
\hline \multirow{2}{*}{$\begin{array}{l}\text { Cubic } \\
\text { zirconia }\end{array}$} & Before aging & 12.1 & 0.22 & 12.11 & 11.82 & 12.45 & 11.94 & 12.26 \\
\hline & After aging & 10.97 & 0.2 & 10.99 & 10.63 & 11.26 & 10.82 & 11.12 \\
\hline \multirow{2}{*}{$\begin{array}{c}\text { Tetragonal } \\
\text { zirconia }\end{array}$} & Before aging & 8.51 & 0.18 & 8.53 & 8.13 & 8.75 & 8.38 & 8.65 \\
\hline & After aging & 6.9 & 0.21 & 6.94 & 6.44 & 7.16 & 6.75 & 7.05 \\
\hline
\end{tabular}


TABLE (2) Descriptive statistics for flexural strength (MPa) values

\begin{tabular}{ccccccccc}
\hline \multirow{2}{*}{ Zirconia type } & Aging & Mean & SD & Median & Minimum & Maximum & \multicolumn{2}{c}{$95 \%$ CI } \\
\cline { 6 - 9 } $\begin{array}{c}\text { Cubic } \\
\text { zirconia }\end{array}$ & Before aging & 534.7 & 142.4 & 572.1 & 298.7 & 791.1 & 432.8 & 636.5 \\
\hline $\begin{array}{c}\text { Tetragonal } \\
\text { zirconia }\end{array}$ & Befter aging & 444.9 & 118.3 & 468.2 & 241 & 590.6 & 360.3 & 529.6 \\
\hline
\end{tabular}

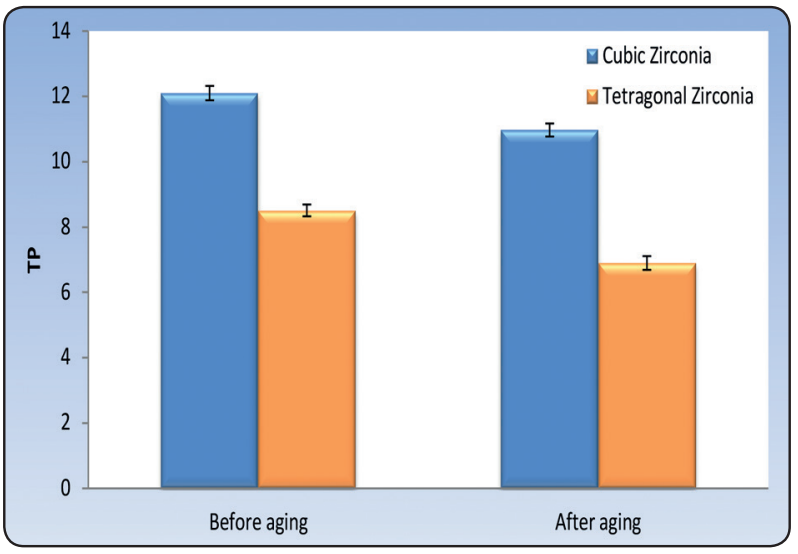

Results of Translucency:

\section{DISCUSSION}

Traditional zirconia material (3Y-TZP) has been used as a dental restorative material for over a decade, due to its high mechanical properties compared with other dental ceramics. But low translucency of conventional zirconia remains a most important problem especially when used in anterior region..$^{\text {[9] }}$

This study was done to evaluate flexural strength before and after accelerating aging for two different types of zirconia material (high translucent tetragonal and ultra high translucent cubic zirconia).

The null hypothesis of this study that there is no difference in flexural strength between HT tetragonal and UHT cubic zirconia before and after aging is rejected.

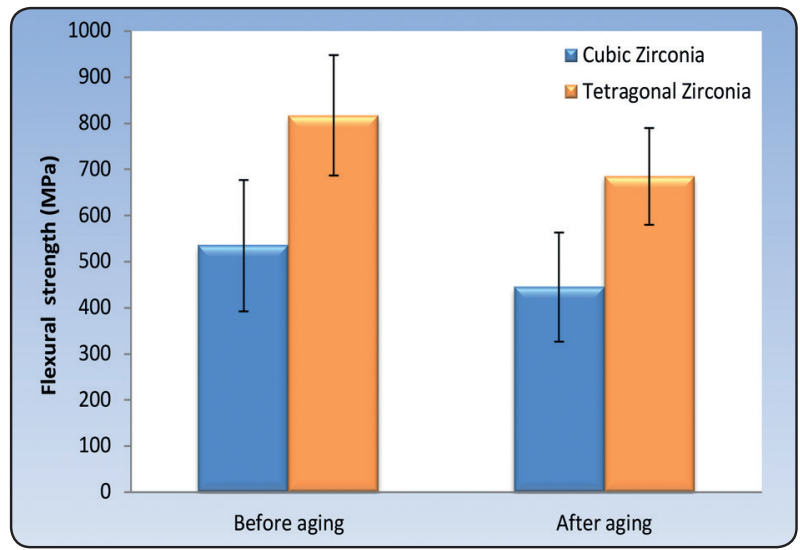

Results of flexural strength

Basílio M, et al (2016) stated that aging of zirconia material by low temperature degradation is usually conducted in an autoclave, through the effect of pressure of water vapor, temperature and time. This humid environment increase $\mathrm{t}-\mathrm{m}$ transformation leads to volume increase of surface grains causes stress propagation from one transformed grain to the others, this is responsible to initiate microcracks helping water to penetrate into the bulk of the material and significantly reduce the mechanical properties. ${ }^{[10]}$ There are some controversies between the aging periods in the literature. Periods were widely different in the studies. The aging periods were $\left(5,10,20,30,80,100\right.$ hours). ${ }^{[11,12,13,14,15,16]}$ Camposilvan E, et al (2018) stated that one hour of accelerated aging at $134^{\circ} \mathrm{C}$ is approximately equal to 2 - 4 years at $37{ }^{\circ} \mathrm{C}$ in the oral cavity. [4] In our study aging was done for 10 hours at $134 \mathrm{C}^{\circ}$ and a 
pressure of 2 bar. This represents average 30 years inside patient mouth.

In our study biaxial flexural strength test was performed through three piston and supporting balls and a significant difference was showed between HT and UHT before and after aging.

Results of UHT cubic zirconia showed that statistically significantly higher mean TP $(12.1 \pm$ $0.22)$ than HT tetragonal Zirconia $(8.51 \pm 0.18)$ regardless Zirconia type; the mean translucent parameter value before aging showed statistically significantly higher value $(10.31 \pm 1.85)$ than after aging $(8.93 \pm 2.1)$. These results agree with results of Alghazzawi T (2016) who found that the mean translucent parameter value before aging showed statistically significantly higher value than after aging and contrast ratio before aging showed statistically significantly lower value than after aging. This could be explained due to transformation from tetragonal to monoclinic phase with associated surface roughness which caused an increase in light scattering. ${ }^{[17]}$

After aging UHT cubic Zirconia showed statistically significantly higher mean translucent parameter $(10.97 \pm 0.2)$ than HT tetragonal Zirconia $(6.9 \pm 0.21)$ and UHT cubic Zirconia showed statistically significantly lower mean contrast ratio $(0.704 \pm 0.005)$ than HT tetragonal zirconia $(803 \pm 0.005)$. This is in agreement with the results of Klimke J, et al (2011) could be due to the presence of cubic phase and stable birefringence that leads to less diffuse scattering at the grain boundaries, pores and high alumina contents that was responsible for formation of secondary phase. Translucency of tetragonal zirconia increased by reducing alumina content without effect on mechanical properties. ${ }^{[3]}$

Regarding flexural strength test, UHT cubic zirconia showed statistically significantly lower mean value $(489.8 \pm 135.5)$ than HT tetragonal Zirconia $(751.1 \pm 133.8)$. These results came in agreement with Kwon S, et al (2018) who showed that tetragonal zirconia recorded flexural strength mean value higher than cubic zirconia. This could be due to lower potential for transformation toughening of UHT cubic than HT tetragonal. The results showed different values than our study due to different specimen shapes that were used (bar versus square). ${ }^{[1]}$

Aging had no significant effect on flexural strength of cubic zirconia in our study, mean value before aging was $(534.7 \pm 142.4)$ and after aging

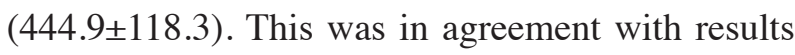
of Camposilvan E, et al (2018) who stated that the presence of cubic phase has main advantages of complete absence of degradation. ${ }^{[7]}$

This was not in agreement with the results of Guilardi L, et al (2017) who showed that mean flexural strength for control group of zirconia was $932 \mathrm{MPa}$ and after aging was 1018.8 MPa. But the cause of increasing flexural strength after aging procedures was not explained. ${ }^{[12]}$

Mean flexural strength of HT tetragonal zirconia; before aging $(817.4 \pm 130.5)$ showed statistically significantly higher value than after aging $(684.9 \pm 104.9)$. This agreed with the results of Zhuang Y, et al (2018) that could be due to transformation from tetragonal to monoclinic phase. However the degree of transformation varied between the groups, so the percentage of monoclinic phase increased with aging time. The grain size after autoclaving varied between different groups according to the thickness of the specimen suggested and the depth of the LTD was influenced by the Y-TZP thickness. Micro cracks formed at the surface layer lead to decrease the flexural strength and fracture strength with increase depth of the transformation zone. ${ }^{[14]}$

\section{Limitations of present study}

The specimens shape were selected as square to facilitate cutting and decreasing the inherited flaws within the specimen, despite that number of studies 
showed no difference in stress distribution or flexural strength values, yet the ISO standard (6872:2008) stated a circular shape should be utilized.

This study was comparative between different zirconia microstructures regardless the anatomical shape and thickness of restorations. Anatomical crowns are expected to have different flexural strength values

Moreover, lack of mechanical aging and thermo-cycling may have affected the translucent parameter and flexural strength if compared to clinical conditions.

\section{CONCLUSIONS}

Within the limitations of this in-vitro study, the following conclusions could be drawn:

1. Ultra high translucent cubic zirconia has more significant translucency after aging than high translucent tetragonal zirconia.

2. UHT zirconia has significantly less flexural strength after aging than HT zirconia.

3. Flexural strength of UHT zirconia has no significant affect by aging. Aging affects significantly the translucency of zirconia regardless the type used.

\section{REFERENCES}

1. Walczak K, Meißner H, Range U. Translucency of Zirconia Ceramics before and after Artificial Aging 2018:1-6. https://doi.org/10.1111/jopr.12771.

2. Pekkan G, Pekkan K, Bayindir BÇ, Özcan M, Karasu B. Factors affecting the translucency of monolithic zirconia ceramics: A review from materials science perspective. Dent Mater J 2020;39:1-8. https://doi.org/10.4012/ dmj.2019-098.

3. Klimke J, Trunec M, Krell A. Transparent tetragonal yttriastabilized zirconia ceramics: Influence of scattering caused by birefringence. J Am Ceram Soc 2011;94:1850-8. https://doi.org/10.1111/j.1551-2916.2010.04322.x.

4. Camposilvan E, Leone R, Gremillard L, Sorrentino R,
Zarone F, Ferrari M, et al. Aging resistance, mechanical properties and translucency of different yttria-stabilized zirconia ceramics for monolithic dental crown applications . Dent Mater 2018;34:879-90. https://doi.org/10.1016/j. dental.2018.03.006.

5. Kou W, Garbrielsson K, Borhani A, Carlborg M, Molin Thorén M. The effects of artificial aging on high translucent zirconia. Biomater Investig Dent 2019;6:54-60. https:// doi.org/10.1080/26415275.2019.1684201.

6. Agingu C, Jiang NW, Cheng H, Yu H. Effect of Different Coloring Procedures on the Aging Behavior of Dental Monolithic Zirconia. J Spectrosc 2018;2018. https://doi. org/10.1155/2018/2137091.

7. Harry P. Papanagiotou, DDS, MSD, a Steven M. Morgano, DMD, b Russell A. Giordano, DMD, DMSc, c and Richard Pober S. In vitro evaluation of low-temperature aging effects and finishing procedures on the flexural strength and structural stability of Y-TZP dental ceramics Harry. J Prosthet Dent 2006;87:288-95. https://doi.org/10.1016/j. jmbbm.2018.07.041.

8. Stawarczyk B, Özcan M, Hallmann L, Ender A, Mehl A, Hämmerlet CHF. The effect of zirconia sintering temperature on flexural strength, grain size, and contrast ratio. Clin Oral Investig 2013;17:269-74. https://doi. org/10.1007/s00784-012-0692-6.

9. Rondoni D. Zirconia: some practical aspects from the technologist's point of view. Int J Esthet Dent 2016;11: 270-4.

10. Basílio M de A, Cardoso KV, Antonio SG, Rizkalla AS, Santos Junior GC, Arioli Filho JN. Effects of artificial aging conditions on yttria-stabilized zirconia implant abutments. J Prosthet Dent 2016;116:277-85. https://doi. org/10.1016/j.prosdent.2016.01.011.

11. De Souza GM, Zykus A, Ghahnavyeh RR, Lawrence SK, Bahr DF. Effect of accelerated aging on dental zirconiabased materials.J Mech Behav Biomed Mater 2017;65:25663. https://doi.org/10.1016/j.jmbbm.2016.08.023.

12. Zhuang Y, Zhu Z, Jiao T, Sun J. Effect of Aging Time and Thickness on Low-Temperature Degradation of Dental Zirconia 2018:1-7. https://doi.org/10.1111/jopr.12946.

13. Agingu C, Jiang NW, Cheng H, Yu H. Effect of Different Coloring Procedures on the Aging Behavior of Dental Monolithic Zirconia. J Spectrosc 2018;2018. https://doi. org/10.1155/2018/2137091. 
14. Roy ME, Noel OF, Whiteside LA. Phase Transformation and Roughening in Artificially Aged and Retrieved Zirconia-Toughened Alumina Femoral Heads. J Arthroplasty 2019;34:772-80. https://doi.org/10.1016/j. arth.2018.12.025.

15. Ahmed D, Mandour M,El-Sharkawy Z. Optical Properties and Flexural Strength of Artificially Aged Tetragonal/Cubic UltraTranslucent Zirconia. Al-Azhar Dent J Girls 2020;7:135-42. https://doi.org/10.21608/adjg.2019.9681.1123.
16. Lemons J, Liu P, Essig ME, Bartolucci AA, Janowski GM. Influence of Low-Temperature Environmental Exposure on the Mechanical Properties and Structural Stability of Dental Zirconia 2012;00:1-7. https://doi.org/10.1111/ j.1532-849X.2011.00838.x.

17. $\mathrm{T}$ A. Original article The effect of extended aging on the optical properties of different zirconia materials. J Prosthodont Res 2016:1-10. https://doi.org/10.1016/j. jpor.2016.11.002. 